\title{
POST LOAD INSULIN VS. FASTING LEVELS IN PREDICTION OF TYPE 2 DIABETES IN WOMEN WITH PCOS
}

Sumarac-Dumanovic M, Micic D, Stamenkovic-Pejkovic D, Cvijovic G, Gligic A, Jeremic D, Milin-Lazovic J School of Medicine, University of Belgrade, Clinic for Endocrinology, Diabetes and Diseases of Metabolism,

Clinical Center of Serbia, Belgrade, Serbia

\section{Introduction and the aim of this study}

Women with polycystic ovary syndrome (PCOS) are at increased risk of developing insulin resistance (IR) and T2DM. In this study, we attempted to detect IR parameters that could be the best predictor T2DM in PCOS comparing to controls.

\section{Description of methods/design:}

- In 130 women with PCOS $\left(\mathrm{BMl}=29.7 \pm 0.66 \mathrm{~kg} / \mathrm{m}^{2}\right.$; age: $\left.25.6 \pm 0.59 \mathrm{yrs}\right)$ and

- 41 controls (age and BMI matched) $\left(B M l=28.5 \pm 1.35 \mathrm{~kg} / \mathrm{m}^{2}\right.$; age: $26.5 \pm 0.89 \mathrm{yrs}$ ).

- OGTT and IVGTT (minimal model analyses) were performed.

-All women has normal fasting glucose, but 16 PCOS women had post load glucose level (120min) over $7,8 \mathrm{mmol} / \mathrm{l}$.

\section{Results:}

After excluding PCOS women with IGT, there was no difference between fasting glucose, but (OGTT) were still higher in PCOS $(\mathrm{P}<0.05)$. was significantly higher in PCOS

(PCOS vs. control)(17.02 \pm 1.07 vs.12.54 \pm 1.72$)$ as well as

(86.85 $\pm 7.18 v s .56 .31 \pm 10.57)$.

There was no statistically significant difference between

(PCOS vs. control)(10417.12 \pm 733.14 vs.8098.36 \pm 1098.2$)$.

Minimal model confirmed no difference in

between 2 groups

between PCOS and controls and in

Si parameter of insulin sensitivity was significantly lower in PCOS

(PCOS vs. control)( (2.46 $\pm 0.18 \mathrm{vs} .3 .59 \pm 0.39)$.

(DI) were significantly higher in controls

(PCOS vs. control)( (166.57 $\pm 13.9 v s .220 .89 \pm 33.47)$.

Additional analyses of 2 PCOS subgroups with normal (NGT) and impaired glucose tolerance (IGT) showed: significant lower Si in IGT subgroup, not different AIR, lower DI.

The best correlation with Si (from minimal model) showed OGIS $(0.490, p<0.01$ ) ( glucose 0,90 i 120 min and insulin at 0 and $90 \mathrm{~min})$, weaker correlation showed HOMA index $(0.271 ; p<0.01)$ and fasting insulin $(-0.247$, $p<0.01)$.

\section{Conclusion}

These insulin sensitivity indexes could be potentially used to identify subgroups of insulin resistant PCOS women with increased risk of T2DM. Our result suggests that indexes included basal and post load glucose and insulin constitute a more sensitive tool for screening metabolic abnormalities in PCOS. 